Article

\title{
Optimization of Electro-Discharge Texturing Parameters for Steel Sheets' Finishing Rollers
}

\author{
Emil Evin ${ }^{1, *}$, Miroslav Tomáš ${ }^{1}$ and Jozef Kmec ${ }^{2}$ \\ 1 Department of Automotive Production, Faculty of Mechanical Engineering, Technical University of Košice, \\ Mäsiarska 74, 04001 Košice, Slovakia; miroslav.tomas@tuke.sk \\ 2 Department of Physics, Mathematics and Technics, Faculty of Humanities and Natural Sciences, \\ Presov University, Ul. 17 novembra 1, 08116 Prešov, Slovakia; jozef.kmec@unipo.sk \\ * Correspondence: emil.evin@tuke.sk; Tel.: +421-55-602-3547
}

Received: 3 February 2020; Accepted: 5 March 2020; Published: 9 March 2020

check for updates

\begin{abstract}
Exterior car-body parts are made of steel or aluminum sheets. Their formability and appearance after painting depends not only on the mechanical properties but also on their surface texture. The surface roughness characteristics, the roughness average $R a$ and the peak count $P c$ per centimeter depend on the texture of rolling mill's finishing rollers, their wear and the degree of removal by the rolling mill. The research was carried out on heat-treated finishing rollers on the surface of which a controlled texture was created by changing the electro-discharge texturing (EDT) parameters. Parameters and the number of electro-discharge texturing experiments were optimized using full four-factor experiment techniques at the upper and lower levels of the parameters in the form of $2^{4}$. The significance of the impact of individual EDT parameters and their interactions was identified based on the variance results. The ANOVA variance analysis results confirmed that the roughness $R a$ and the peak count $P_{c}$ depend primarily on peak current $\left(I_{p}\right)$, discharge peak voltage $\left(U_{p}\right)$, pulse on time $\left(P_{\text {ont }}\right)$ and pulse off time $\left(P_{\text {offt }}\right)$. Optimization of the effect of the above parameters on the target roughness $R a_{T, F R}$ values and the peak count $P_{c_{T, F R}}$ of finishing rollers was performed by the response surface methodology (RSM). Obtained regression models describe relationships between the input parameters of the electro-discharge texturing of finishing rollers and the output characteristics of the $R a_{T, F R}$ and the $P c_{T, F R}$ texture to a very high degree. The reliability of the electro-discharge texturing process of working rollers was assessed using the process capability index $C_{p k}$.
\end{abstract}

Keywords: finishing rollers; controlled texture; statistical methods; mean arithmetic roughness; peak count; reliability indices; ANOVA; design of experiment

\section{Introduction}

When presented with a choice of similar products sold at a similar price on the market, the customer often makes a choice based on their quality. The concept of quality is very broad and largely depends on the customer's individual requirements. As the quantity of goods on offer increases, the quality requirements become more and more objective. The quality of products is characterized by a set of measurable features, which allow it to be monitored and controlled. For example, in the case of sheets for the car-body panels, not only are the mechanical properties of the sheets emphasized, the texture of their surfaces also receives due attention to guarantee the formability and appearance of the body parts after painting. The regulated texture of the sheet metal surfaces helps to retain the lubricant on the tool's contact surfaces during the forming processes and thus contributes to improve their formability and final appearance of body parts after painting [1-3]. 
The sheets for the car-body parts are manufactured in a special mode on the galvanizing line, which includes more thorough strip input control (cleanliness, geometry, surface defects, etc.), annealing speed, galvanizing bath parameters, rolling mill parameters and finishing roller texture parameters $\left(R a_{F R}\right.$ roughness and peak count $\left.P c_{F R}\right)$. During the finishing rolling, the texture of rolling mill's finishing rollers is transferred to the surface of the steel sheet. Transfer of the texture from rollers to the sheet surface depends largely on removal done by the rolling mill, the texture of finishing rollers and the wear of finishing rollers. The wear of finishing rollers also depends on the texturing technology. When the texture is done by shot blasting technology (SBD) the wear is up to $38 \%$, for electro-discharge technology (EDT) the wear is up to $32 \%$, for hard chromed electro-discharged texture (EDT Hard Chrome) the wear is up to $23 \%$ and for Topocrom technology the wear is up to $8 \%[4,5]$.

Individual car manufacturers require different target values of sheet metal texture. Hence, Skoda Auto requires for the steel sheets when used for the outside car body parts the arithmetic mean roughness value $R a=1.1-1.6 \mu \mathrm{m}$ and the peak count $P c \geq 40 \mathrm{~cm}^{-1}$; Ford requires the arithmetic mean roughness value $R a=1.1-1.7 \mu \mathrm{m}$ and the peak count $P c \geq 50 \mathrm{~cm}^{-1}$ and Volkswagen requires the arithmetic mean roughness value $R a=1.1-1.6 \mu \mathrm{m}$ and the peak count $P c \geq 60 \mathrm{~cm}^{-1}$ [4,5]. The desired texture values of the sheet metal surfaces cannot be achieved by rolling mills with rollers mechanically blasted with fine-grain shots (SBT-shot blast texturing). Mechanical blasting of working rollers results in a stochastic texture creation, which cannot be controlled. For these reasons, use of stochastic systems of texturing finishing rollers by the method of shot blast texturing has been abandoned in favor of deterministic texturing systems: electric discharge texturing (EDT), laser beam texturing (LBT), electron beam texturing (EBT) or the Topocrom method [4-7].

In application of electro-discharge texturing, the material is removed by repeated discharges that cause local melting or evaporation of material from the surface of the heat-treated roller [8]. The resulting texture of working rollers depends on the size of craters, or on the amount of material removed $Q_{v i}$.

$$
Q_{v i}=k \cdot f \cdot r \cdot k_{e} \cdot E_{i}\left(\mathrm{~mm}^{3} \cdot \mathrm{s}\right)
$$

where the amount of energy of a single discharge

$$
E_{i}=\int_{0}^{t} U_{P}(t) \cdot I_{P}(t) \cdot d t(\mathrm{~J})
$$

where $k$ is the proportionality factor for the anode and cathode; $f$ is the discharge frequency $\left(\mathrm{s}^{-1}\right) ; r$ is the electric discharge efficiency (\%); $k_{e}$ is the generator efficiency $(\%) ; E_{i}$ is the single discharge energy $(\mathrm{J}) ; t$ is the length of discharge duration $-P_{\text {ont }}(\mu \mathrm{s}) ; U_{P}$ is the discharge voltage $(\mathrm{V})$ and $I_{P}$ is the peak current (A).

Laser beam texturing (LBM) allows for creation of a regular or pseudo stochastic surface texture with crater overlay and increased wear resistance of the working rollers. Electro-discharge texturing (EDT) can produce a wide range of $R a_{F R}$ roughness from 0.5 to $10 \mu \mathrm{m}$ with a $P c_{F R}$ peak count up to $150 \mathrm{~cm}^{-1}$, with a uniform microrelief surface, good reproducibility of the surface texture of the finishing roller and its transfer to the sheet surface [7]-Table 1. Likewise, electron beam texturing (EBT) opens a large window into creating surfaces with a wide range of $R a_{F R}$ parameters. However, the texture obtained is not the most desirable in terms of tribological conditions on contact surfaces of the die, since worsened sheet formability can be expected as a result.

Topocrom texturing of the working rollers is based on the elimination of chrome hemispherical segments on the surface of the finishing rollers. The number and dimensions of hemispherical segments ( $R a_{F R}$ roughness and the $P c_{F R}$ texture peak count) can be varied to a large extent with a small scatter along the entire length of the finishing roller by changing parameters of electrolytic deposition. Long service life is typical for finishing rollers made by the Topocrom technology [5].

EDT, LBT, EBT and Topocrom working roller processes are progressive, but considerably complicated. Setting these process parameters by trial and error techniques is ineffective. By optimizing 
the input parameters of these processes, it is possible to control the process of texturing the finishing rollers to meet the ever-increasing surface quality requirements of sheets intended for bodywork parts.

Table 1. Comparison of selected parameters for texturing methods.

\begin{tabular}{|c|c|c|c|c|c|}
\hline \multirow[b]{2}{*}{ Parameter } & \multicolumn{5}{|c|}{ Texturing Method } \\
\hline & SBT & EDT & LBT & EBT & Topocrom \\
\hline Irregularities & $\begin{array}{l}\text { Triangular } \\
\text { Trapezoidal }\end{array}$ & Craters & $\begin{array}{l}\text { Craters with } \\
\text { solid collar }\end{array}$ & $\begin{array}{l}\text { Craters with } \\
\text { solid collar }\end{array}$ & $\begin{array}{l}\text { Spherical } \\
\text { segments }\end{array}$ \\
\hline Topography & Random & Random & $\begin{array}{l}\text { Random or } \\
\text { determinate }\end{array}$ & $\begin{array}{l}\text { Random or } \\
\text { determinate }\end{array}$ & Random \\
\hline$R a(\mu \mathrm{m})$ & $1.5-6$ & $0.5-10$ & 0.8-10 & 0.5-20 & $0.5-20$ \\
\hline$P_{c}\left(\mathrm{~cm}^{-1}\right)$ & $<70$ & 50-150 & 50-100 & $50-150$ & 50-200 \\
\hline
\end{tabular}

Studies related to the EDM have shown that the process performance can be considerably improved by properly selecting the process material and operating parameters. Since the EDM process has a very complex nature due to the complicated discharge mechanisms and their interactions, parameter optimization appears to be a hot research area [9]. In [10] authors optimized process parameters after die-sinking EDM of tool steel. They suggested mathematical models for the determination of the optimal combination of significant technological parameters in order to minimize microhardness and total HAZ depth variations of tool steel EN X32CrMoV12-28 after die-sinking EDM with a SF-Cu electrode. Optimization of EDM machining parameters of Inconel 600 was presented in [11]. They analytically modeled the energy density, which is being absorbed by the workpiece and the electrode, and experimentally confirmed that the negative polarity leads to a higher material removal rate, higher electrode wear and higher surface roughness. The effect of pulse current and pulse duration in die-sinking EDM on the machining characteristics of Ti-6Al-4V alloy was studied in [12]. Authors used an electrode wear ratio, the material removal rate and the surface roughness to measure the effect of machining and control charts for controlling the process. EDM process parameters were optimized also for the shape-memory alloy NiTi 60 [13] by applying Taguchi's method considering an orthogonal array of L27 and using Minitab software. In [14] authors used the Taguchi method when studying the effect of the peak current, pulse on time and feed rate on the material removal rate at the EDM of tool steel H-13. In [15] authors used the design of experiment to investigate surface layers properties including roughness 3D parameters, the thickness of the white layer, heat affected zone, tempered layer and occurring micro cracks at EDM of tool steel. Besides, a new method of the EDM process, such as ultrasonic vibration assisted EDM process was developed and optimized [16].

Design of experiments (DoE) techniques provide powerful tools for optimizing process parameters. The design of experiment plan lies in understanding the effect of different variable factors and their interactions. The design of experiment (DoE) is based on different settings of input parameters and observation of corresponding output response. The aim of the designed experiment is to find the relation between independent variables $x_{i}$ and dependent variable $y_{i}$ in mathematical terminology, or the cause and effect relationship. Optimized input parameters obtained by means of design of experiment techniques (DoE) make it possible to take effective measures related to texture control [17-19].

\section{Design of Experiments, Materials and Methods}

At the beginning of the experiment design, input EDT parameters (factors) were defined: peak current $I_{p}$, voltage discharge voltage $U_{p}$, pulse-on time (pulse length) $P_{\text {ont }}$ and pulse-off time (the length of a technological pause) $P_{\text {offt }}$ and other electro-discharge texturing factors (roller speed, feed rate, shape and surface area of electrodes used, material of electrodes used), which may have an effect on the monitored target values of finishing rollers $R a_{T, F R}$ and $P c_{T, F R}[9,20-22]$.

The draft design of the experiment sequence was based on Volkswagen's requirements for the texture characteristics of the sheet steel surfaces intended for bodywork auto body parts. We drew on 
an assumption that the texture of rolling mill's finishing rollers was transferred to the steel sheet's surface during cold rolling as a function of removal and wear of the rollers, or it depends on the number of sheets rolled. This means that the final values of surface texture characteristics $R a_{S S}$ and $P c_{S S}$ of steel sheets can be controlled by controlling the removal made by the rolling mill. The greater the removal, the greater the contouring (transfer) of texture to the sheet surface. For example, a 30-40\% improvement in texture transfer was noted upon the change in removal from $0.7 \%$ to $1.1 \%$. Transfer of texture from the roller to the sheet surface is limited by the maximum possible removal value. As aforementioned, in rollers prepared by the EDT in combination with chrome plating, a reduction in roughness transmission of $R a_{F R}$ by approximately $25 \%$ was due to the roller wear. From these assumptions, the mean value of the target roughness of finishing rollers was established to be 1.6 times the upper roughness value required by Volkswagen on the $R a_{U C L}$ sheet metal surface $\left(R a_{U C L, S S}=\right.$ $1.6 \mu \mathrm{m}$ - upper control line for steel sheet roughness). Thus, the assumed mean target roughness value of finishing rollers $R a_{T, C L, F R}=1.6 \times R a_{U C L, S S} \approx 2.5 \mu \mathrm{m}$. The lower limit of the target roughness value of the designed experiment was set at $2 / 3$ of the upper zone of the maximum roughness value of the sheet metal surface required by the automaker Volkswagen [22,23], i.e., $R a_{T, C L, F R}=R a_{U C L, S S}-1 / 3 T_{S S, R a}=$ $1.53 \mu \mathrm{m}$. The upper limit of the target roughness value of the designed experiment was designed to be $3.8 \mu \mathrm{m}\left(R a_{U C L, F R}=3.8 \mu \mathrm{m}\right)$ also taking into account the roughness tolerance of the working rollers $T_{F R, R a}$. As mentioned, the required roughness values of the sheets intended for the body parts of the car bodies range from 1.1 to $1.7 \mu \mathrm{m}$ or the surface roughness tolerance of sheets intended for body surface parts is $T_{S S, R a}= \pm 0.25 \mu \mathrm{m}$. For each target roughness value, estimated $P c_{F R}$ peak counts were calculated according to Equation (3) [6]:

$$
P C_{F R}=12.9 R a^{2}-102.9 R a+272\left(\mathrm{~cm}^{-1}\right)
$$

According to Equation (3), the target roughness value of the finishing rollers $R a_{T, F R 1}=1.538 \mu \mathrm{m}$ will correspond to the peak count $P c_{T, F R 1, \min }=144 \mathrm{~cm}^{-1}, R a_{T, F R 2}=2.5 \mu \mathrm{m}$ will correspond to the peak count $P c_{T, F R 2, \min }=94 \mathrm{~cm}^{-1}$ and $R a_{T, C U L}=3.8 \mu \mathrm{m}$ will correspond to the peak count $P c_{T, F R 3, \text { min }}=$ $67 \mathrm{~cm}^{-1}$. Texturing was performed on the EDT 2100/4500 device in BP250 oil dielectric with 8 copper electrodes at three different levels of electro-discharge texturing input parameters-Table 2.

Table 2. Input parameters of the electro-discharge texturing process.

\begin{tabular}{cccccc}
\hline Control Factors & Symbol & Unit & Level 1 & Level 2 & Level 3 \\
\hline Peak current & $I_{p}$ & $\mathrm{~A}$ & 4 & 8 & 19 \\
Pulse-on time & $P_{\text {ont }}$ & $\mu \mathrm{s}$ & 4 & 14 & 29 \\
Pulse-off time & $P_{\text {offt }}$ & $\mu \mathrm{s}$ & 6 & 16 & 38 \\
Lower value of discharge voltage & $U_{I L}$ & $\mathrm{~V}$ & 5 & 10 & 15 \\
Upper value of discharge voltage & $U_{I H}$ & $\mathrm{~V}$ & 8 & 20 & 35 \\
Electrode diameter & $U_{p}$ & $\mathrm{~V}$ & 6.5 & 15 & 25 \\
Average value of discharge voltage $\left(U_{I L}+\mathrm{U}_{I H}\right) / 2$ & $D$ & $\mathrm{~mm}$ & 8 & 8 & 8 \\
Target $R a$ value of the finishing rollers & $R a_{T, F r i}$ & $\mu \mathrm{m}$ & 1.5 & 2.5 & 3.8 \\
Target $P c$ value of the finishing rollers & $P_{T, F R i}$ & $\mathrm{~cm}^{-1}$ & 140 & 92 & 62 \\
\hline
\end{tabular}

Sixteen finishing rollers for each level were subjected to observation. Table 3 shows values measured on the monitored surface texture characteristics (responses) of the finishing rollers $R a_{T, F R}$ and $P c_{T, F R}$ at the individual EDT parameter levels. The average value $(\mathrm{AV})$ of the investigated output characteristic $R a_{T, F R i}$, or $P c_{T, F R i}$ was calculated for each data group and so was the standard deviation SD. Finishing roller texture characteristics obtained at three levels of input parameters were evaluated by the Hommel Tester T1000 roughness meter (JENOPTIK Industrial metrology, Villingen-Schwenningen, Germany) along the entire roller length at 9 locations (at three locations at the left edge of the roller, at three locations at the right edge of the roller, and at three locations at the center of the roller) in the respective planes when the roller got turned by $0^{\circ}, 90^{\circ}, 180^{\circ}$ and $270^{\circ}$ according to DIN EN ISO 
12085 [24]. Cut-off length was $l_{r}=0.8 \mathrm{~mm}$ and $l_{n}=4.0 \mathrm{~mm}$ as specified by the device producer for expected Ra values up to $4 \mu \mathrm{m}$. $R a$ and $P_{C}$ values were measured parallel to the roller axis.

Table 3. Measured target roughness $R a_{T, F R i}$ and peak count values $P c_{T, F R i}$ at individual EDM parameter level settings.

\begin{tabular}{|c|c|c|c|c|c|c|}
\hline \multirow{2}{*}{ Number } & \multicolumn{2}{|c|}{ Level 1} & \multicolumn{2}{|c|}{ Level 2} & \multicolumn{2}{|c|}{ Level 3} \\
\hline & $\begin{array}{c}R a_{T, F R 1} \\
(\mu \mathrm{m})\end{array}$ & $\begin{array}{c}P c_{T, F R 1} \\
\left(\mathrm{~cm}^{-1}\right)\end{array}$ & $\begin{array}{c}R a_{T, F R 2} \\
\quad(\mu \mathrm{m})\end{array}$ & $\begin{array}{c}P c_{T, F R 2} \\
\left(\mathrm{~cm}^{-1}\right)\end{array}$ & $\begin{array}{c}R a_{T, F R 3} \\
\quad(\mu \mathrm{m})\end{array}$ & $\begin{array}{l}P c_{T, F R 3} \\
\left(\mathrm{~cm}^{-1}\right)\end{array}$ \\
\hline 1. & 1.554 & 159 & 2.577 & 99 & 3.781 & 73 \\
\hline 2. & 1.493 & 159 & 2.453 & 106 & 3.844 & 74 \\
\hline 3. & 1.545 & 154 & 2.482 & 95 & 3.886 & 68 \\
\hline 4. & 1.563 & 145 & 2.537 & 100 & 3.866 & 69 \\
\hline 5. & 1.495 & 167 & 2.465 & 97 & 3.842 & 66 \\
\hline 6. & 1.498 & 157 & 2.484 & 98 & 3.823 & 66 \\
\hline 7. & 1.507 & 166 & 2.537 & 97 & 3.874 & 66 \\
\hline 8. & 1.495 & 154 & 2.465 & 100 & 3.847 & 70 \\
\hline 9. & 1.516 & 164 & 2.553 & 99 & 3.831 & 63 \\
\hline 10. & 1.578 & 147 & 2.541 & 101 & 3.852 & 65 \\
\hline 11. & 1.538 & 164 & 2.575 & 98 & 3.822 & 71 \\
\hline 12. & 1.564 & 166 & 2.623 & 109 & 3.813 & 68 \\
\hline 13. & 1.543 & 159 & 2.456 & 101 & 3.825 & 68 \\
\hline 14. & 1.557 & 153 & 2.577 & 99 & 3.816 & 65 \\
\hline 15. & 1.494 & 160 & 2.523 & 96 & 3.831 & 68 \\
\hline 16. & 1.573 & 148 & 2.563 & 95 & 3.842 & 90 \\
\hline$A V$ & 1.532 & 158 & 2.481 & 99 & 3.837 & 68 \\
\hline$S D$ & \pm 0.03 & \pm 7 & \pm 0.05 & \pm 3 & \pm 0.03 & \pm 3 \\
\hline$C L$ & 1.538 & 122 & 2.5 & 122 & 3.8 & 122 \\
\hline$U C L$ & 1.788 & - & 2.25 & - & 4.05 & - \\
\hline LCL & 1.288 & $60^{*}$ & 2.75 & $60^{*}$ & 3.55 & $60^{*}$ \\
\hline$C_{p k, U C L}$ & 2.84 & - & 2.99 & - & 2.37 & - \\
\hline$C_{p k, L C L}$ & 2.71 & 4.67 & 2.57 & 4.33 & 3.19 & 0.89 \\
\hline$C L$ & 1.538 & 47 & 2.5 & 47 & 3.8 & 47 \\
\hline UCL & 1.788 & - & 2.25 & - & 4.05 & - \\
\hline$L C L$ & 1.288 & $40^{* *}$ & 2.75 & $40^{* *}$ & 3.55 & $40^{* *}$ \\
\hline$C_{p k, U C L}$ & 2.84 & - & 2.99 & - & 2.37 & - \\
\hline$C_{p k, L C L}$ & 2.71 & 5.62 & 2.57 & 6.56 & 3.19 & 3.11 \\
\hline
\end{tabular}

*Volkswagen's requirements; ${ }^{* *}$ Skoda Auto's requirements.

Mean values and standard deviations of the observed texture characteristics were calculated from repeated experiments at individual target value levels of designed experiments. The texture characteristics were investigated based on the proposed full Type $2^{4}$ Factor Plan, varying the $I_{p}, U_{p}$, $P_{\text {ont }}$ and $P_{\text {offt }}$ EDT (factor) settings of input parameters. After starting the process, the input parameters changed only at the upper and lower levels. In its individual lines, the experiment design shows the conditions under which the experiments were carried out in random order-Table 4.

Evaluation of the experimental results was carried out using the statistical software Minitab 16. Conversion of natural to dimensionless variables $a_{i}$ was done using the coding relationship (4):

$$
a_{i}= \pm 1=\frac{x_{i j}-x_{0 i}}{\Delta x_{i}}
$$

where the baseline $i$-th factor $x_{o i}=\left(x_{H i}+x_{D i}\right) / 2$ and $i$-th factor variation interval $\Delta x_{i}=\left(x_{H i}-x_{D i}\right) / 2[25,26]$.

Using statistical methods of the designed experiment in Minitab 16 makes it possible to:

- Mathematically describe the dependence of the texture characteristics of the finishing rollers $R a_{F R i}$ and $P c_{F R i}$ on the input factors $I_{p}, U_{P}, P_{\text {ont }}$ and $P_{\text {offt }}$; 
- Find the optimal combination of input factor settings,

- Filter out noise factors or their interaction in carrying out a minimum number of experiments $[25,26]$.

Table 4. Setting the upper and lower levels of the electro-discharge texture parameters and the full experiment design response $2^{4}$.

\begin{tabular}{|c|c|c|c|c|c|c|c|c|}
\hline \multirow{2}{*}{$\begin{array}{l}\text { Run } \\
\text { Order }\end{array}$} & \multirow{2}{*}{$\begin{array}{c}\text { Center } \\
\text { Pt }\end{array}$} & \multirow{2}{*}{ Blocks } & \multicolumn{4}{|c|}{ Analyzed Factors } & \multicolumn{2}{|c|}{ Responses } \\
\hline & & & $P_{o n t}(\mu \mathrm{s})$ & $P_{o f f t}(\mu \mathrm{s})$ & $I_{P}(\mathrm{~A})$ & $U_{P}(\mathrm{~V})$ & $\begin{array}{l}\text { Roughness } \\
R a_{T, F R}(\mu \mathrm{m})\end{array}$ & $\begin{array}{c}\text { Number of Peaks } \\
\qquad c_{T, F R}\left(\mathrm{~cm}^{-1}\right)\end{array}$ \\
\hline 1 & 1 & 1 & 29 & 6 & 19 & 6.5 & 2.750 & 73 \\
\hline 2 & 1 & 1 & 29 & 38 & 4 & 25 & 2.970 & 73 \\
\hline 3 & 1 & 1 & 4 & 38 & 4 & 25 & 2.433 & 95 \\
\hline 4 & 1 & 1 & 29 & 38 & 19 & 25 & 3.820 & 71 \\
\hline 5 & 1 & 1 & 4 & 6 & 19 & 25 & 3.096 & 73 \\
\hline 6 & 1 & 1 & 4 & 38 & 19 & 25 & 3.096 & 73 \\
\hline 7 & 1 & 1 & 4 & 6 & 19 & 6.5 & 2.214 & 96 \\
\hline 8 & 1 & 1 & 4 & 38 & 4 & 6.5 & 1.551 & 118 \\
\hline 9 & 1 & 1 & 4 & 6 & 4 & 25 & 2.433 & 95 \\
\hline 10 & 1 & 1 & 4 & 38 & 19 & 6.5 & 2.214 & 96 \\
\hline 11 & 1 & 1 & 29 & 6 & 4 & 6.5 & 2.087 & 96 \\
\hline 12 & 1 & 1 & 29 & 6 & 19 & 25 & 3.632 & 50 \\
\hline 13 & 1 & 1 & 29 & 38 & 4 & 6.5 & 2.087 & 96 \\
\hline 14 & 1 & 1 & 4 & 6 & 4 & 6.5 & 1.551 & 158 \\
\hline 15 & 1 & 1 & 29 & 6 & 4 & 25 & 2.970 & 73 \\
\hline 16 & 1 & 1 & 29 & 38 & 19 & 6.5 & 2.750 & 73 \\
\hline
\end{tabular}

\section{Analysis of the results obtained}

The calculated mean values of the target roughness values $R a_{T, F R 1}=1.5358 \mu \mathrm{m}, R a_{T, F W 2}=2.5 \mu \mathrm{m}$ and $R a_{T, T W 3}=3.8 \mu \mathrm{m}$ were plotted in control charts-Figures 1 and 2 . In control charts, central lines (central line $C L_{R a}$ ) have been indicated, the values of which equal the target values of the analyzed characteristics $R a_{T, F R i}$ and $P c_{T, F R i}$ for each range level. Subsequently, control limits, i.e., the lower control limit ( $L C L_{R a}$-lower control limit) and the upper control limit (UCL $L_{R a}$-upper control limit) were indicated, the values of which were calculated from target values of monitored texture characteristics of working rollers and their tolerances-Figure 2. In establishing the $L C L_{R a}$ and $U C L_{R a}$ control limits, we assumed that the texture of the finishing rollers is transferred to the surface of the steel sheet during cold rolling as a function of removal and the number of the sheets rolled (wear of the working rollers).

$$
T_{S S, R a}=T_{T, F R, R a}= \pm 0.25 \mu \mathrm{m}
$$

then

$$
\begin{aligned}
& U C L_{R a}=R a_{T, F R i}-T_{S S, R a} / 2 \\
& L C L_{R a}=R a_{T, F R i}+T_{S S, R a} / 2
\end{aligned}
$$

and the EDT process capability index:

$$
\begin{gathered}
C_{p k U C L}=\frac{U C L-\bar{y}}{3 T_{F R} / 2} \\
C_{p k L C L}=\frac{\bar{y}-L C L}{3 T_{F R} / 2}
\end{gathered}
$$

where $\bar{y}$ is the mean value of the monitored output characteristics $R a_{T, F R i}$ and $P c_{T, F r i \text { min }}$ in individual groups [27]. 


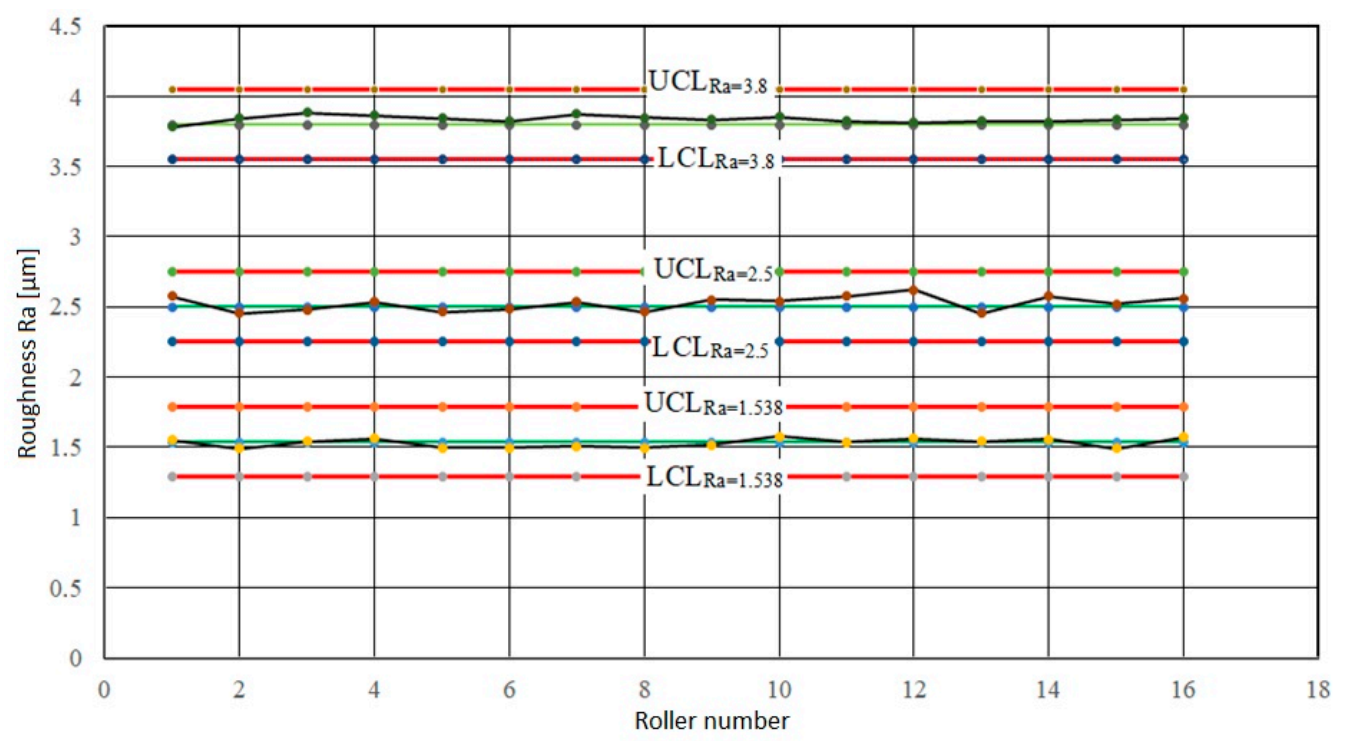

Figure 1. Control charts for target roughness values $R a_{T, F r i}$.

Figure 1 shows that the 1-16 roller roughness values with the $R a_{T, F R i}$ roughness values were in the first band ( $1 / 3$ of the tolerance) of the control boundaries. The calculated $C_{p k}$ values in all three cases were greater than 1.33. This means that the EDT work procedures applied to each target group were capable of repeatedly achieving the desired target roughness values $R a_{T, F R i}$.

As mentioned in previous research, automakers require different minimum values for the peak count $P c_{S S \text {, min }}$ per centimeter, ranging between 40 and $60 \mathrm{~cm}^{-1}$ in sheets intended for the bodywork parts. If the minimum value of the monitored output characteristic is required, it is indicated in the control charts as $L C L_{P c}$ as it is shown in Figure 2:

$$
L C L_{P c}=P C_{S S, \min }
$$

The position of the central line in control charts was:

$$
C L_{P c, \min }=L C L_{P c}+S D_{P c, \max }
$$

where $T_{P_{c}}$ is the peak count tolerance $T_{n}=S D_{P_{c}, \max }=7 \mathrm{~cm}^{-1}$ or $3 \mathrm{~cm}^{-1}$ as it is shown in Table 3 .

Figure 2 shows that the process of roller texturing should be capable of repeatedly creating a texture with target roughness values $R a_{T, F R 1}=1.538$ and $R a_{T, F R 2}=2.5 \mu \mathrm{m}$ with $P c_{T, V W, \min }=60 \mathrm{~cm}^{-1}$ as required by the Volkswagen. Since the measured peak count values were above the lower $L C L_{P C}$ $=P c_{V W}$ limit and the process capability index was greater than 1.33-see Table 3. Peak counts for target roughness values $R a_{T, F R 3}=3.8 \mu \mathrm{m}$ were below the lower limit of the required minimum peak count, and $C_{p k, P c}$ capability indices were less than 1.33-see Figure 2 and Table 3. This means that the process of texturing the finishing rollers with the target value $R a_{T, F R 3}=3.8 \mu \mathrm{m}$ was not capable of repeatedly achieving the texture with the peak count greater than $60 \mathrm{~cm}^{-1}$. When setting the EDT process parameters of the finishing rollers listed in Table 2, it can be assumed that for the required values of $R a_{T, F R}=2.5 \mu \mathrm{m}$ and $R a_{T, F R}=3.8 \mu \mathrm{m}$, requirements of both Ford and Skoda could also be met $\left(P c_{T, S A, \min }=40 \mathrm{~cm}^{-1}\right)$. For target roughness values ranging from 1.538 to $3.5 \mu \mathrm{m}$ and a minimum peak count greater than 40 , the process capability index $C_{p k, P c}>1.33$ - see Table 3. 


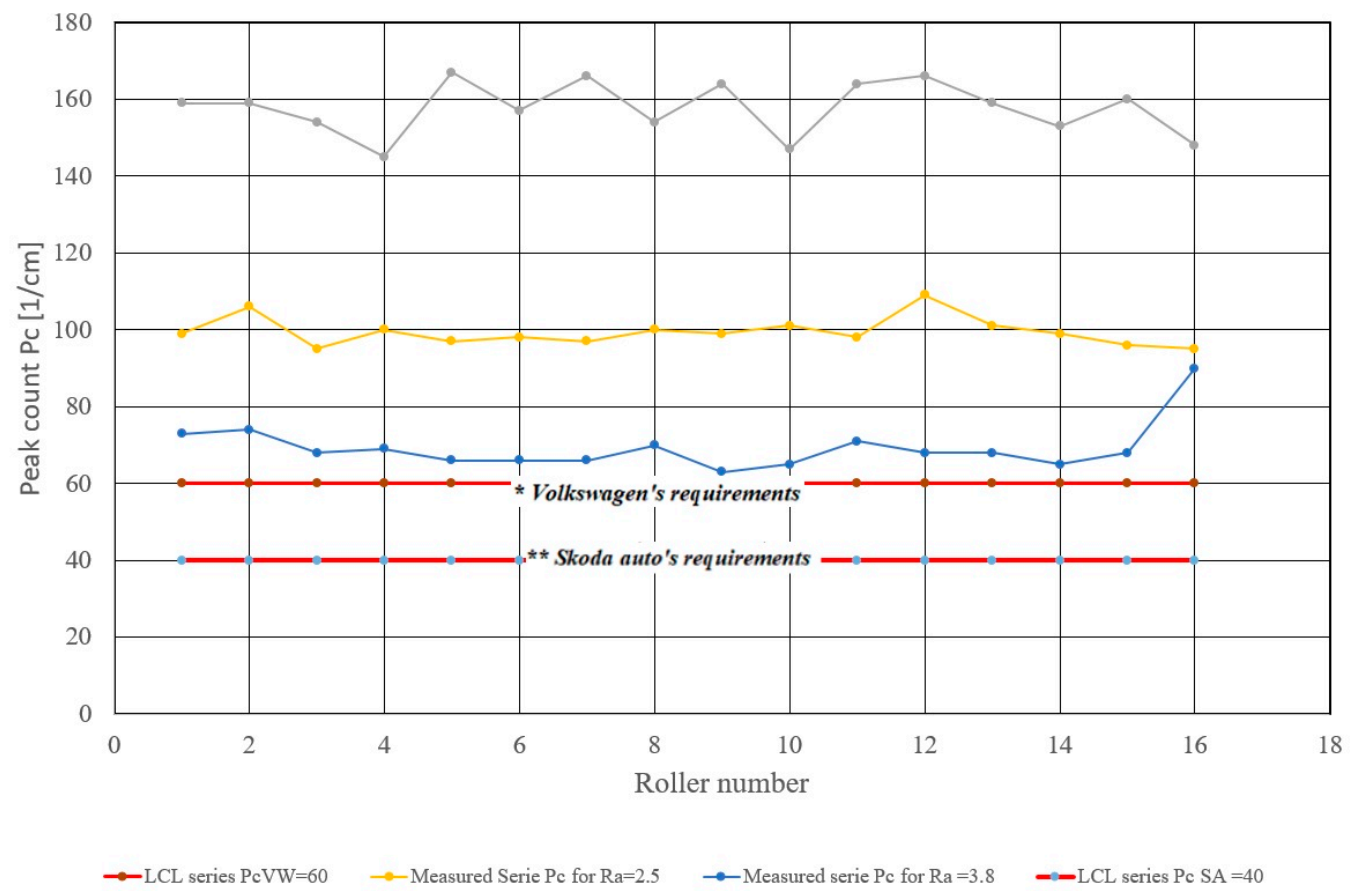

Figure 2. Control charts of the minimum peak count $P c_{\text {min }}$.

\subsection{Testing the Significance by a $t$-Test}

Based on the above results, further research focused on finding an input parameter setting that would make it possible to obtain the $R a_{F R i}$ values ranging between 1.538 and $3.5 \mu \mathrm{m}$ while maintaining the peak count of $P c_{F, W V, \text { min }}>60 \mathrm{~cm}^{-1}$ or $P c_{F, S A, \text { min }}>40 \mathrm{~cm}^{-1}$. In order to achieve this goal, the results were analyzed using a complete factor experiment $2^{4}$, with the application of mathematical-statistical methods in the environment of Minitab 16-see Tables 5-8. The F-test and the $t$-test, respectively were used to test the significance of the influence of parameters applied to the EDT process levels on the roughness $R a_{T, F R i}$ and the peak count of $P c_{T, F R, \min }$. The results of the ANOVA analysis done in Minitab 16 software at a significance level of $95 \%$ using the $t$-test and the $F$-test were processed graphically and tabularly-Tables 5-8 and Figures 3 and 4 .

Table 5. Estimated effects and coefficients for roughness (coded units).

\begin{tabular}{cccccc}
\hline Term & Effect & Coef & SE Coef & $T$ & $p$-Value \\
\hline Constant & - & 2.57975 & 0.04645 & 55.54 & 0.000 \\
$P_{\text {ont }}$ & 0.44350 & 0.22175 & 0.04645 & 4.77 & 0.005 \\
$P_{\text {offt }}$ & 0.64225 & 0.32112 & 0.04645 & 6.91 & 0.001 \\
$I_{p}$ & 0.45000 & 0.22500 & 0.04645 & 4.84 & 0.005 \\
$U_{p}$ & 0.64075 & 0.32038 & 0.04645 & 6.90 & 0.001 \\
$P_{\text {ont }} \cdot P_{\text {offt }}$ & 0.09325 & 0.04663 & 0.04645 & 1.00 & 0.363 \\
$P_{\text {ont }} \cdot I_{P}$ & -0.09300 & -0.04650 & 0.04645 & -1.00 & 0.364 \\
$P_{\text {ont }} \cdot U_{P}$ & 0.09275 & 0.04637 & 0.04645 & 1.00 & 0.363 \\
$P_{\text {off }} \cdot I_{P}$ & 0.09275 & 0.04637 & 0.04645 & 1.00 & 0.364 \\
$P_{\text {offt }} \cdot U_{P}$ & -0.09300 & -0.04650 & 0.04645 & -1.00 & 0.363 \\
$I_{P} \cdot U_{P}$ & 0.09275 & 0.04638 & 0.04645 & 1.00 & 0.364 \\
\hline- & $S$ & $P R E S S$ & $R-S q$ & $R-S q(p r e d)$ & $R-S q(a d j)$ \\
- & 0.185800 & 1.76751 & $96.72 \%$ & $66.45 \%$ & $90.17 \%$ \\
\hline
\end{tabular}


Table 6. Estimated effects and coefficients for the number of peaks (coded units).

\begin{tabular}{cccccc}
\hline Term & Effect & Coef & SE Coef & $\boldsymbol{T}$ & $p$-Value \\
\hline Constant & - & 112.69 & 0.1008 & 1118.17 & 0.000 \\
$P_{\text {ont }}$ & -22.62 & -11.31 & 0.1008 & -112.25 & 0.000 \\
$P_{\text {offt }}$ & -22.62 & -11.31 & 0.1008 & -112.25 & 0.000 \\
$I_{p}$ & -22.62 & -11.31 & 0.1008 & -112.25 & 0.000 \\
$U_{p}$ & -22.62 & -11.31 & 0.1008 & -112.25 & 0.000 \\
$P_{\text {ont }} \cdot P_{\text {offt }}$ & -0.12 & -0.06 & 0.1008 & -0.62 & 0.562 \\
$P_{\text {ont }} \cdot I_{P}$ & -0.12 & -0.06 & 0.1008 & -0.62 & 0.562 \\
$P_{\text {ont }} \cdot U_{P}$ & -0.12 & -0.06 & 0.1008 & -0.62 & 0.562 \\
$P_{\text {off }} \cdot I_{P}$ & -0.13 & -0.06 & 0.1008 & -0.62 & 0.562 \\
$P_{\text {offt }} \cdot U_{P}$ & -0.13 & -0.06 & 0.1008 & -0.62 & 0.562 \\
$I_{P} \cdot U_{P}$ & -0.12 & -0.06 & 0.1008 & -0.62 & 0.562 \\
\hline- & $S$ & $P R E S S$ & $R-S q$ & $R-S q($ pred $)$ & $R-S q(a d j)$ \\
- & 0.403113 & 8.32 & $99.99 \%$ & $99.90 \%$ & $99.97 \%$ \\
\hline
\end{tabular}

The hypothesis tested is the effect of the factors tested or that of their interactions to the surface texture parameters is significant. The statistical significance of individual factors and their interaction was expressed using the $p$-value. If $\alpha \geq p$, the null hypothesis $H_{0}$ is rejected and the alternative hypothesis $H_{1}$ is accepted. This means that the effect of factors tested or that of their interactions is significant for a given significance level $\alpha$. Conversely, if $\alpha<p$, the null hypothesis $H_{0}$ must be accepted. This means that the effect of individual factors or their interactions is insignificant $[25,26]$.

Table 7. Regression analysis: roughness versus on, off, current and voltage.

\begin{tabular}{ccccc}
\hline Predictor & Coef & SE Coef & $T$ & $p$ \\
\hline Constant & 0.906 & 0.1500 & 6.03 & 0.000 \\
$P_{\text {ont }}$ & 0.0177 & 0.0037 & 4.77 & 0.001 \\
$P_{\text {offt }}$ & 0.0201 & 0.0029 & 6.91 & 0.000 \\
$I_{P}$ & 0.0300 & 0.0062 & 6.84 & 0.001 \\
$U_{P}$ & 0.0366 & 0.0053 & 6.90 & 0.000 \\
- & $S=0.186$ & $R$-Sq $=92.8 \%$ & $R$-Sq(adj) $=90.2 \%$ & \\
\hline
\end{tabular}

Table 8. Regression analysis: number of peaks versus on, off, current and voltage.

\begin{tabular}{ccccc}
\hline Predictor & Coef & SE Coef & $T$ & $p$ \\
\hline Constant & 181.5 & 0.265 & 684.19 & 0.000 \\
$P_{\text {ont }}$ & -0.9050 & 0.006571 & -137.72 & 0.000 \\
$P_{\text {offt }}$ & -0.7070 & 0.005134 & -137.72 & 0.000 \\
$I_{P}$ & -1.5083 & 0.01095 & -137.72 & 0.000 \\
$U_{P}$ & -1.2929 & 0.00939 & -137.72 & 0.000 \\
- & $S=0.3286$ & $R-S q=100.0 \%$ & $R-S q(a d j)=100.0 \%$ & \\
\hline
\end{tabular}

The signal-to-noise $(\mathrm{S} / \mathrm{N})$ ratio method was used to optimize the selected response variables. Based on the selected response characteristic, a larger-the-better $\mathrm{S} / \mathrm{N}$ ratio has been used in this research work $[27,28]$. It follows from the analysis presented in Tables 5 and 6 that the $p$-value for individual factors was less than 0.05 , therefore the alternative hypothesis $H_{1}$ was accepted. The average roughness values $R a_{T, F R i}$ at the set levels of factors $I_{P}, U_{P}, P_{\text {ont }}$ and $P_{\text {offt }}$ were not equal to each other, therefore, it could be stated that their influence on the significance level $\alpha=0.05$ was statistically significant. In case of mutual interactions of the monitored factors, the null hypothesis was not rejected because the $p$-values of the test criterion were greater than 0.05 , their effect on the resulting roughness at the significance level $\alpha=0.05$ was statistically insignificant. 


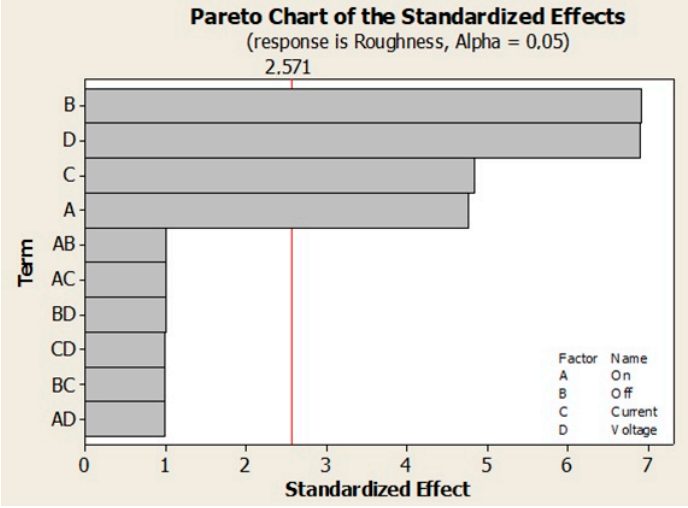

(a)

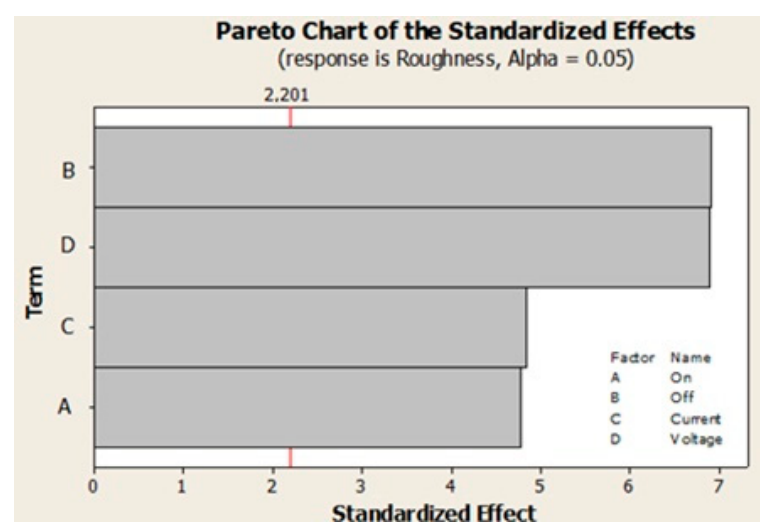

(b)

Figure 3. Effect of individual factors on Ra roughness: (a) with noise and (b) without noise.

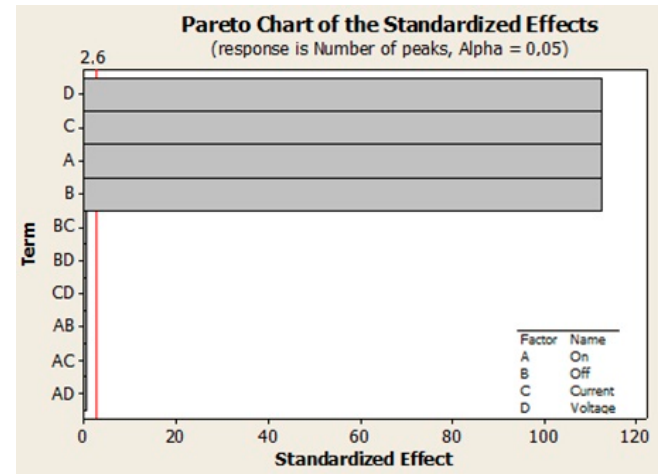

(a)

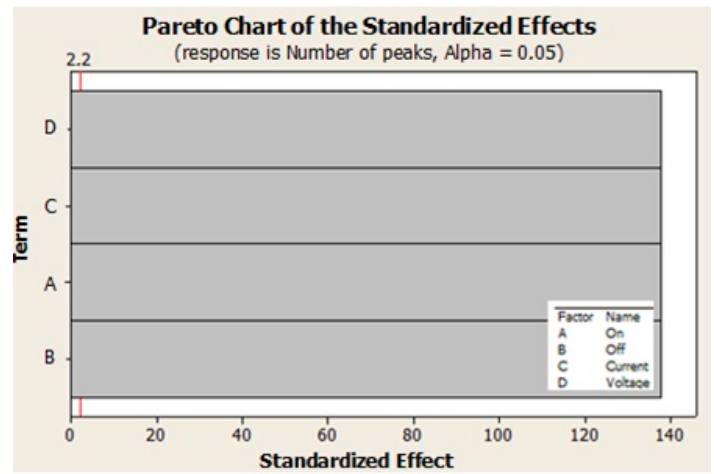

(b)

Figure 4. Effect of individual factors on Pc peak count: (a) with noise and (b) without noise.

On the basis of the calculated regression coefficients shown in Table 5, it is possible to write a model regression equation predicting the $R a_{F R i}$ roughness with the noise taken into account in the following form:

$$
\begin{aligned}
R a_{F R i}=2.58+ & 0.222 P_{\text {ont }}+0.321 P_{\text {offt }}+0.225 I_{P}+0.32 U_{P}+0.047 P_{\text {ont }} P_{\text {offt }}-0.047 P_{\text {ont }} I_{P} \\
& +0.046 P_{\text {ont }} U_{P}+0.046 P_{\text {off }} I_{P}-0.047 P_{\text {off }} U_{P}+0.046 I_{P} U_{P}
\end{aligned}
$$

and after neglecting the noise, the model regression equation can be written in a simpler form:

$$
R a_{F R i}=0.906+0.0177 P_{\text {ont }}+0.0201 P_{\text {offt }}+0.03 I_{P}+0.0366 U_{p}
$$

The overall informative level of the prediction Model (12) and Model (13) was given by the multiple determination coefficient $R-S q(a d j)=90.27 \%$ and the correlation coefficient $R=0.95$. Based on the multiple determination coefficient $R-S q$ (adj) and the correlation coefficient, it can be stated that Model (12) and Model (13) could predict the roller roughness with a probability of $95 \%$.

Similarly as mentioned for the average roughness values $R a_{T, F R i}$, the model predicting the peak count based on calculated values of regression coefficients shown in Table 6 can be written in the form:

$$
\begin{gathered}
P C_{F R}=112.7-11.31 P_{\text {ont }}-11.31 P_{\text {offt }}-11.31 I_{P}-11.31 U_{P}-0.06 P_{\text {ont }} P_{\text {offt }}-0.06 P_{\text {ont }} \\
-0.06 P_{\text {ont }} U_{P}-0.06 P_{\text {offt }} I_{P}-0.06 P_{\text {off }}-0.06 I_{P} U_{P}
\end{gathered}
$$

and after neglecting the noise, the model regression equation can be written in a simpler form:

$$
P C_{F R}=181.5-0.905 P_{\text {ont }}-0.707 P_{\text {offt }}-1.508 I_{P}-1.293 U_{p}
$$


The value of the multiple regression coefficient $R-S q$ (adj) model for the $P c_{F R}$ peak count prediction was $100 \%$, and similarly, the correlation coefficient $R=1$. Thus, it can be stated that Models (14) and (15) could predict the peak count with $100 \%$ probability.

From the analysis of deviations of factors listed in Table 5 and Figure 3 it follows that regardless of the fact whether noise is or is not taken into account, the greatest influence on the $R a_{F R}$ roughness is that of the $P_{\text {offt }}$ factor and the smallest is that of the $P_{\text {ont }}$ factor, while their interactions are insignificant. From the analysis of deviations of factors listed in Table 6 and Figure 4 follows that individual factors $P_{\text {ont }}, P_{\text {offt }}, I_{P}$ and $U_{P}$ have the same effect on the $P c_{F R}$ peak count, while their mutual interactions are insignificant.

\subsection{Testing the Significance by the F-Test}

The results obtained from the designed experiment were also tested using the F-test, which is based on the significance of the difference between two variations. The decomposition of total variability into its individual parts makes it possible to find out the main source of variability and factors that show a significant effect on the resulting values of $R a_{F R}$ roughness and the $P c_{F R}$ peak count. The result of the test is a comparison of the critical value of $F \alpha ; a-1 ; \mathrm{N}-a$ with the value of the test criterion $F$. Similarly to the $t$-test, the $F$-test makes it easier and quicker to establish the significance of individual factors using the $p$-value. Tables 9 and 10 show that the $p$-value for each factor was less than 0.05 , and Table 11 shows estimated coefficients for roughness and for the number of peaks. This means that the effect of individual factors $\left(P_{\text {ont }}, P_{\text {oft }}, I_{P}\right.$ and $U_{P}$ ) on the average roughness values of $R a_{F R i}$ was statistically significant. As shown in Tables 9 and 10, in cases of a mutual interaction of the monitored factors, the null hypothesis could not be rejected, because the $p$-values of the test criterion were greater than 0.05 - the mutual interactions of the factors were insignificant.

Table 9. Analysis of variance for roughness (coded units).

\begin{tabular}{|c|c|c|c|c|c|c|}
\hline Source & DF & Seq SS & Adj SS & Adj MS & $F$ & $p$-Value \\
\hline Main Effects & 4 & 4.999 & 4.999 & 1.222 & 35.40 & 0.001 \\
\hline$P_{\text {ont }}$ & 1 & 0.787 & 0.787 & 0.787 & 22.79 & 0.005 \\
\hline$P_{\text {offt }}$ & 1 & 1.650 & 1.650 & 1.650 & 47.79 & 0.001 \\
\hline$I_{P}$ & 1 & 0.810 & 0.810 & 0.810 & 23.46 & 0.005 \\
\hline$U_{P}$ & 1 & 1.642 & 1.642 & 1.642 & 47.57 & 0.001 \\
\hline 2-Way Interactions & 6 & 0.207 & 0.207 & 0.035 & 1 & 0.510 \\
\hline$P_{\text {ont }} \cdot P_{\text {Offt }}$ & 1 & 0.035 & 0.035 & 0.035 & 1 & 0.362 \\
\hline$P_{\text {ont }} \cdot I_{P}$ & 1 & 0.035 & 0.035 & 0.035 & 1 & 0.363 \\
\hline$P_{\text {ont }} \cdot U_{P}$ & 1 & 0.034 & 0.034 & 0.034 & 1 & 0.364 \\
\hline$P_{o f f t} \cdot I_{P}$ & 1 & 0.034 & 0.034 & 0.034 & 1 & 0.364 \\
\hline$P_{\text {offt }} \cdot U_{P}$ & 1 & 0.035 & 0.035 & 0.035 & 1 & 0.363 \\
\hline$I_{P} \cdot U_{P}$ & 1 & 0.034 & 0.034 & 0.034 & 1 & 0.364 \\
\hline Residual Error & 5 & 0.173 & 0.173 & 0.035 & & \\
\hline \multirow[t]{2}{*}{ Total } & 15 & & & & & \\
\hline & & Jnusual Obse & ations for & ghness & & \\
\hline Obs & StdOrder & Roughness & Fit & SE Fit & Residual & St Resid \\
\hline 15 & 6 & 1.874 & 2.106 & 0.154 & -0.232 & $-2.24 R$ \\
\hline
\end{tabular}


Table 10. Analysis of variance for the number of peaks (coded units).

\begin{tabular}{ccccccc}
\hline Source & DF & Seq SS & Adj SS & Adj MS & $\boldsymbol{F}$ & $p$-Value \\
\hline Main Effects & 4 & 8190.25 & 8190.25 & 2047.56 & $12,600.38$ & 0.000 \\
$P_{\text {ont }}$ & 1 & 2047.56 & 2047.56 & 2047.56 & $12,600.38$ & 0.000 \\
$P_{\text {offt }}$ & 1 & 2047.56 & 2047.56 & 2047.56 & $12,600.38$ & 0.000 \\
$I_{P}$ & 1 & 2047.56 & 2047.56 & 2047.56 & $12,600.38$ & 0.000 \\
$U_{P}$ & 1 & 2047.56 & 2047.56 & 2047.56 & $12,600.38$ & 0.000 \\
2-Way Interactions & 6 & 0.307 & 0.307 & 0.006 & 0.38 & 0.862 \\
$P_{\text {ont }} \cdot P_{\text {offt }}$ & 1 & 0.006 & 0.006 & 0.006 & 0.38 & 0.562 \\
$P_{\text {ont }} \cdot I_{P}$ & 1 & 0.006 & 0.006 & 0.006 & 0.38 & 0.562 \\
$P_{\text {ont }} \cdot U_{P}$ & 1 & 0.006 & 0.006 & 0.006 & 0.38 & 0.562 \\
$P_{\text {offt }} \cdot I_{P}$ & 1 & 0.006 & 0.006 & 0.006 & 0.38 & 0.562 \\
$P_{\text {offt }} \cdot U_{P}$ & 1 & 0.006 & 0.006 & 0.006 & 0.38 & 0.562 \\
$I_{P} \cdot U_{P}$ & 1 & 0.006 & 0.006 & 0.006 & 0.38 & 0.562 \\
Residual Error & 5 & 0.81 & 0.81 & 0.16 & & \\
Total & 15 & 8191.44 & & & & \\
Obs & StdOrder & Roughness & Fit & SE Fit & Residual & St Resid \\
15 & 6 & 1.874 & 2.106 & 0.154 & -0.232 & $-2.24 \mathrm{R}$ \\
\hline
\end{tabular}

Table 11. Estimated coefficients for roughness and for the number of peaks using data in uncoded units.

\begin{tabular}{ccc}
\hline Term & Coef for Roughness & for Number of Peaks \\
\hline Constant & 1.121 & 181 \\
$P_{\text {ont }}$ & 0.0114 & -0.881 \\
$P_{\text {offt }}$ & 0.0172 & -0.689 \\
$I_{P}$ & 0.0182 & -1.470 \\
$U_{P}$ & 0.0288 & -1.263 \\
$P_{\text {ont }} \cdot P_{\text {offt }}$ & 0.00023 & $-3.12 \times 10^{-4}$ \\
$P_{\text {ont }} \cdot I_{P}$ & -0.000496 & $-6.70 \times 10^{-4}$ \\
$P_{\text {ont }} \cdot U_{P}$ & 0.00042 & $-5.71 \times 10^{-4}$ \\
$P_{\text {offt }} \cdot I_{P}$ & 0.00039 & $-5.21 \times 10^{-4}$ \\
$P_{\text {offt }} \cdot U_{P}$ & -0.00033 & $-4.46 \times 10^{-4}$ \\
$I_{P} \cdot U_{P}$ & 0.00071 & -0.00095 \\
\hline
\end{tabular}

On the basis of the calculated regression coefficients shown in Table 11, it is possible to write a model regression equation predicting the $R a_{F R}$ roughness with the noise taken into account in the following form:

$$
\begin{aligned}
& R a_{F R i}=1.121+0.0114 P_{\text {ont }}+0.017 P_{\text {offt }}+0.018 I_{P}+0.029 U_{P}+0.00023 P_{\text {ont }} P_{\text {offt }} \\
& \quad-0.000496 P_{\text {ont }} I_{P}+0.00042 P_{\text {ont }} U_{P}+0.00039 P_{\text {off } f} I_{P}-0.00033 P_{\text {off }} U_{P} \\
& \quad+0.00071 I_{P} U_{P}
\end{aligned}
$$

On the basis of the calculated regression coefficients shown in Table 11, it is possible to write a model regression equation predicting the $P c_{F R i}$ roughness with the noise taken into account in the following form:

$$
\begin{gathered}
P C_{F R}=181-0.881 P_{\text {ont }}-0.689 P_{\text {offt }}-1.47 I_{P}-1.263 U_{P}-0.000312 P_{\text {ont }} P_{\text {offt }}-0.00067 P_{\text {ont }} I_{P} \\
-0.000571 P_{\text {ont }} U_{P}-0.000521 P_{\text {offt }} I_{P}-0.000446 P_{\text {offt }} U_{P}-0.00095 I_{P} U_{P}
\end{gathered}
$$

Figure 5 shows that with increasing values of investigated factors $\left(I_{P}, P_{\text {ont }}, P_{\text {offt }}\right.$ and $\left.U_{P}\right)$ between the lower and upper levels, the $R a_{F R i}$ roughness increased. In the case of an increase in the $R a_{F R i}$ roughness, the increase was smaller at the lower level of the factors than at the upper level of the factors investigated-Figure 5b. This means that by increasing the EDT parameters at the upper level, a significant improvement in the spark discharge effect was achieved. Depending on the peak count 
of the individual investigated factors (Figure 6) it follows that with increasing values of investigated factors in the range between the lower and the upper level, the opposite effect was achieved, i.e., with increasing values of the investigated EDT factors, there was a decrease in the number of $P c_{F R i}$ peak count. Greater effect can be expected when changing the parameters of the EDT process in the lower level area of individual factor parameters than in the area of the upper level-Figure $6 \mathrm{~b}$.

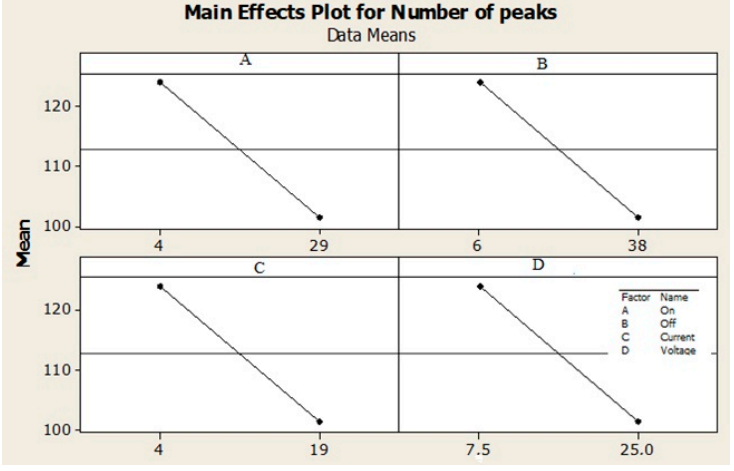

(a)

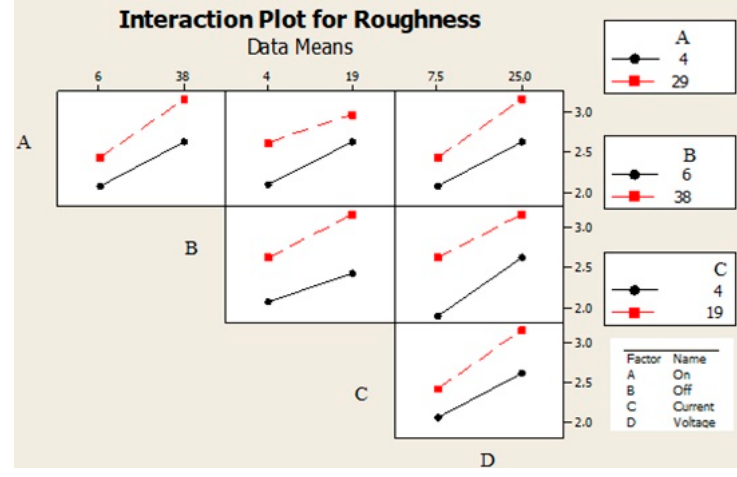

(b)

Figure 5. Plot for $R a_{F R}$ roughness: (a) the main effect and (b) interactions.

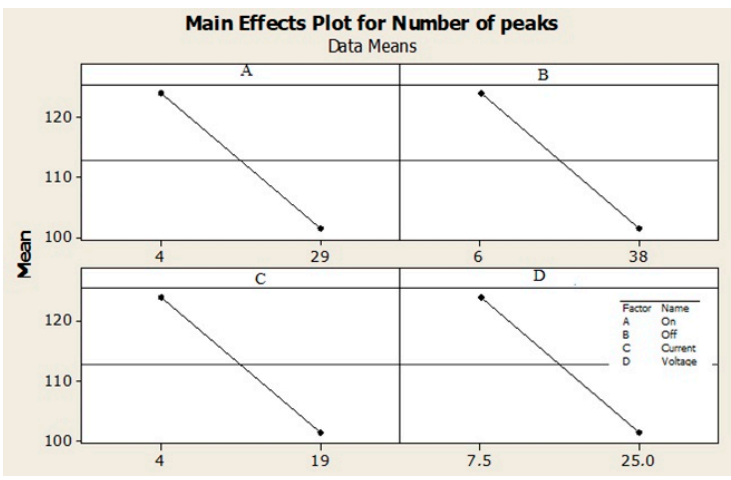

(a)

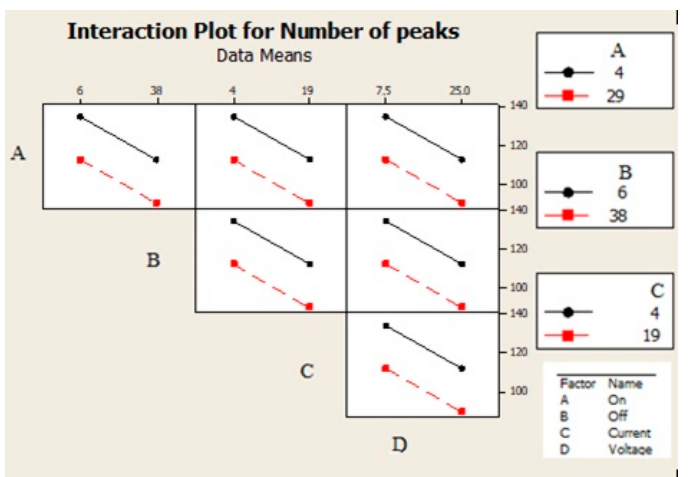

(b)

Figure 6. Plot for $P c_{F R}$ peak count: (a) the main effect and (b) interactions.

The F-test results confirmed that the parameters applied to the roller texturing process should be capable of repeatedly creating the texture with $R a_{T, F R 1}=1.538 \mu \mathrm{m}$ as well as the texture with $R a_{T, F R 2}$ $=2.5 \mu \mathrm{m}$, both fulfilling $P c_{T, F R 1, \min }>60 \mathrm{~cm}^{-1}$, as required by the automaker Volkswagen. Since the measured peak count values were above the lower $L C L_{\text {Pclimit }}$ and the process capability index was greater than 1.33. Table 3 and Figure 2 show that the process of texturing the working rollers with the target value $R a_{T, F R 3}=3.8 \mu \mathrm{m}$ was not capable of repeatedly achieving a texture with a peak count $P_{C_{T, F R 1, \text { min }}}>60 \mathrm{~cm}^{-1}$, because the $C_{p k P c}$ capability indices were less than 1.33 .

When setting the EDT process parameters listed in Table 2, it can be assumed that the texture with $R a_{T, F R i}$ will be repeatedly achieved, ranging between 1.538 and $3.8 \mu \mathrm{m}$ and, at the same time, the peak count $P c_{T, F R 2 \text { min }}>40 \mathrm{~cm}^{-1}$, as required by Skoda. At the target roughness values ranging from 1.538 to $3.5 \mu \mathrm{m}$, the minimum peak count was greater than 40 and the capability index $C_{p k P C}>1.33-$ Table 4 .

The C-E (Cause and Effects) analysis of errors on the finishing rollers after EDT showed that the rollers are most often damaged by burns, forming strips along the roller circumference and its length. The roller gets burns due to setting of a short technological pause or low speed, which does not eliminate impurities from the dielectric fluid and reforms the arc between the electrode and the finishing roller. This undesirable effect can be avoided by prolonging the technological pause at an interval at which the electric discharge channel regenerates in the spark gap. If this does not 
correct the error, the roller speed must be increased. The risk of other errors can be eliminated by regular maintenance.

\section{Optimization of the EDT Factors' Effect on Surface Texture Characteristics}

Response surface methodology (RSM) was used to optimize the EDT factors' effect on surface texture characteristics. RSM is a collection of mathematical and statistical techniques useful for analyzing problems in which several independent variables influence a dependent variable or response, and the goal is to optimize this response. In many experimental conditions, it is possible to represent independent factors in the quantitative form [29].

Optimal values of EDT input parameters to achieve the target $R a_{T, F R i}$ roughness values ranging from 1.538 to $3.8 \mu \mathrm{m}$ and a minimum peak count $P C_{T, F R 1, \min }>60 \mathrm{~cm}^{-1}$ (Volkswagen requirement) or minimum peak count $P c_{T, F R 2, \min }>40 \mathrm{~cm}^{-1}$ (Skoda requirement) were established by the response surface methodology (RSM). These two output characteristics $R a_{T, F R i}$ and $P c_{T, F R i \text { min }}$ of the surface of finishing rollers show a contradictory tendency. During optimization, priority was given to achieving the target values of $R a_{T, F R 1}=1.538 \mu \mathrm{m}, R a_{T, F R 2}=2.5 \mu \mathrm{m}$ and $R a_{T, F R 3}=3.5 \mu \mathrm{m}$. The target roughness values of $R a_{T, F R i}$, their lower and upper values, their weight and importance were defined at the input and optimized values of the input parameters $\left(P_{\text {ont }}, P_{\text {offt }}, I_{P}\right.$ and $\left.U_{P}\right)$ were calculated based on these input data. The results of the response optimization for the desired roughness target values $R a_{T, F R i}$ are shown in Tables 12-14 and Figure 7. Based on the optimized values of the $P_{\text {ont }}, P_{\text {offt }}, I_{P}$ and $U_{P}$ parameters, the values of the peak count were calculated using the regression models (14) and (17)-Tables 12-14.

Table 12. Input and output electro-discharge texturing (EDT) parameters for target roughness $R a_{T, F R 1}$ $=1.538 \mu \mathrm{m}$.

\begin{tabular}{|c|c|c|c|c|c|c|}
\hline Parameters & Goal & Lower & Target & Upper & Weight & Import \\
\hline Roughness & Target & 1.538 & 1.539 & 3.714 & 1 & 1 \\
\hline \multicolumn{7}{|c|}{ Starting Point } \\
\hline$P_{\text {ont }}$ & $P_{o f f t}$ & $I_{p}$ & $U_{p}$ & & & \\
\hline 4 & 6 & 4 & 7.5 & & & \\
\hline \multicolumn{4}{|c|}{ Global Solution } & \multicolumn{3}{|c|}{ Predicted Responses } \\
\hline$P_{\text {ont }}$ & $P_{\text {offt }}$ & $I_{p}$ & $U_{p}$ & $\begin{array}{l}\text { Roughness } \\
\qquad a(\mu \mathrm{m})\end{array}$ & $\begin{array}{c}\text { Peak Count } \\
\text { PC }\left(\mathrm{cm}^{-1}\right) \\
(14)\end{array}$ & $\begin{array}{c}\text { Peak } \\
\text { Count } \\
\text { Pc }\left(\mathrm{cm}^{-1}\right) \\
(17)\end{array}$ \\
\hline 4.29 & 6.32 & 4.47 & 8.1 & 1.539 & 159 & 156 \\
\hline \multirow{2}{*}{\multicolumn{4}{|c|}{$\begin{array}{l}\text { Process capability indices } C_{p k, U C L} \\
\text { Process capability indices } C_{p k, L C L}\end{array}$}} & 2.77 & & \\
\hline & & & & & 4.71 & 4.57 \\
\hline
\end{tabular}

Table 13. Input and output EDT parameters for target roughness $R a_{T, F R 2}=2.5 \mu \mathrm{m}$.

\begin{tabular}{|c|c|c|c|c|c|c|}
\hline Parameters & Goal & Lower & Target & Upper & Weight & Import \\
\hline Roughness & Target & 1.538 & 2.5 & 3.714 & 1 & 1 \\
\hline \multicolumn{4}{|c|}{ Starting Point } & \multicolumn{2}{|c|}{-} & - \\
\hline$P_{\text {ont }}$ & $P_{\text {offt }}$ & $I_{p}$ & $U_{p}$ & - & - & - \\
\hline \multirow[t]{2}{*}{4} & 6 & 4 & 7.5 & - & - & - \\
\hline & \multicolumn{3}{|c|}{ Global Solution } & \multicolumn{3}{|c|}{ Predicted Responses } \\
\hline$P_{\text {ont }}$ & $P_{o f f t}$ & $I_{p}$ & $U_{p}$ & $\begin{array}{c}\text { Roughness } \\
\qquad a(\mu \mathrm{m})\end{array}$ & $\begin{array}{c}\text { Peak Count } \\
\text { PC }\left(\mathrm{cm}^{-1}\right) \\
(14)\end{array}$ & $\begin{array}{c}\text { Peak } \\
\text { Count } \\
P c\left(\mathrm{~cm}^{-1}\right) \\
(17)\end{array}$ \\
\hline 4.86 & 6.97 & 15.1 & 25 & 2.5 & 121 & 118 \\
\hline \multirow{2}{*}{\multicolumn{4}{|c|}{$\begin{array}{l}\text { Process capability indices } C_{p k, U C L} \\
\text { Process capability indices } C_{p k, L C L}\end{array}$}} & 2.78 & - & - \\
\hline & & & & - & 6.78 & 6.44 \\
\hline
\end{tabular}


Table 14. Input and output EDT parameters for target roughness $R a_{T, F R 3}=3.5 \mu \mathrm{m}$.

\begin{tabular}{|c|c|c|c|c|c|c|}
\hline Parameters & Goal & Lower & Target & Upper & Weight & Import \\
\hline Roughness & Target & 1.538 & 3.5 & 3.714 & 1 & 1 \\
\hline \multicolumn{4}{|c|}{ Starting Point } & \multicolumn{2}{|l|}{8.} & - \\
\hline$P_{\text {ont }}$ & $P_{\text {offt }}$ & $I_{p}$ & $U_{p}$ & - & - & - \\
\hline \multirow{2}{*}{4} & 6 & 4 & 7.5 & - & - & - \\
\hline & \multicolumn{3}{|c|}{ Global Solution } & \multicolumn{3}{|c|}{ Predicted Responses } \\
\hline$P_{\text {ont }}$ & $P_{\text {offt }}$ & $I_{p}$ & $U_{p}$ & $\begin{array}{l}\text { Roughness } \\
\qquad a(\mu \mathrm{m})\end{array}$ & $\begin{array}{c}\text { Peak Count } \\
P_{C}\left(\mathrm{~cm}^{-1}\right) \\
(14)\end{array}$ & $\begin{array}{c}\text { Peak } \\
\text { Count } \\
\text { Pc }\left(\mathrm{cm}^{-1}\right) \\
(17)\end{array}$ \\
\hline 19.53 & 38 & 19 & 25 & 3.5 & 92 & 78 \\
\hline \multirow{2}{*}{\multicolumn{4}{|c|}{$\begin{array}{l}\text { Process capability indices } C_{p k, U C L} \\
\text { Process capability indices } C_{p k, L C L}\end{array}$}} & 2.77 & - & - \\
\hline & & & & - & 3.56 & 2.00 \\
\hline
\end{tabular}

Figure 7a shows that with the combination of optimized EDT parameters $\left(P_{\text {ont }}=4.29 \mu \mathrm{s}, P_{\text {offt }}=\right.$ $6.32, I_{P}=4.47 \mathrm{~A}$ and $\left.U_{P}=8.1 \mathrm{~V}\right)$, required target roughness values $R a_{T, F R 1}=1.539 \mu \mathrm{m}$ were achieved. The total composite desirability when using RSM for predicted responses or the roughness target was at level 1. Thus, the response $\left(R a_{T, F R 1}\right)$ has reached an ideal state-it is within an acceptable interval. The minimum peak count $P c_{T, F R 1}=156 \mathrm{~cm}^{-1}$ was established by calculation according to the regression Models (14) and (17), at which a coefficient of determination $R-S q$ (adj) of $99.97 \%$ and a coefficient of correlation $R=1$ were recorded.

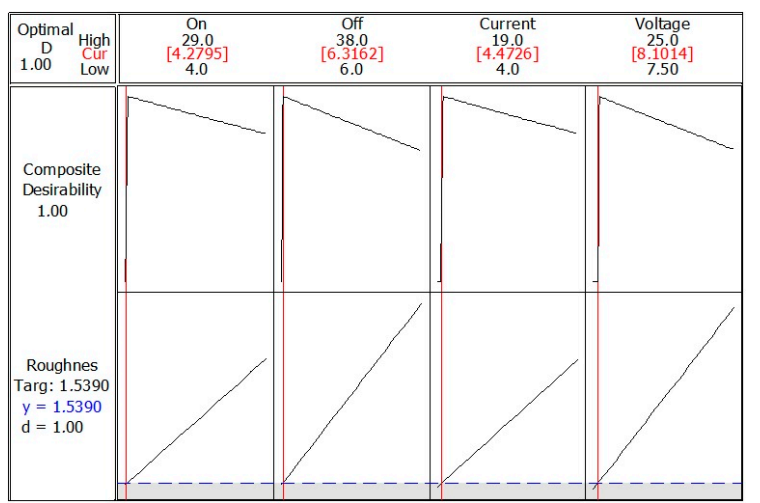

(a)

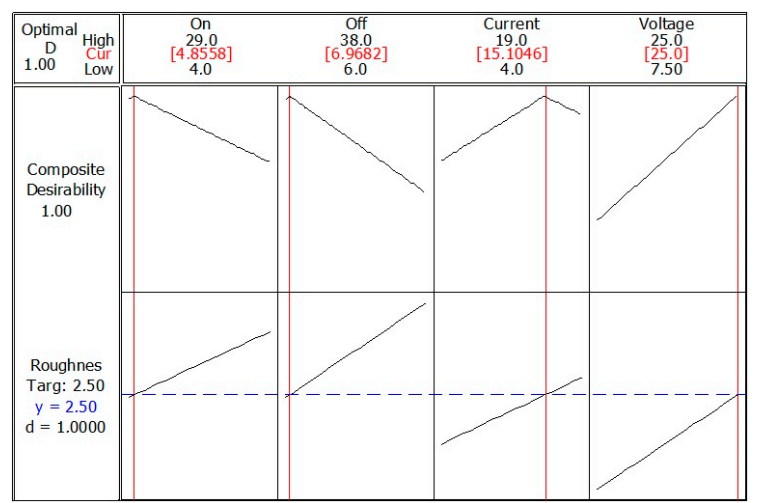

(b)

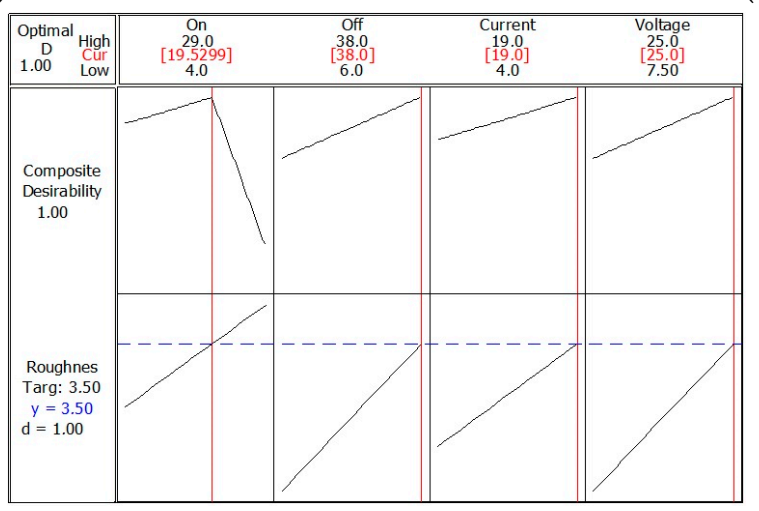

(c)

Figure 7. Optimization of EDT input parameters to achieve the roughness target value: (a) $R a_{T, F R 1}=$ $1.538 \mu \mathrm{m}$; (b) $R a_{T, F R 2}=2.5 \mu \mathrm{m}$ and (c) $R a_{T, F R 3}=3.5 \mu \mathrm{m}$.

Figure $7 \mathrm{~b}$ shows that with the combination of the optimized EDT parameters $\left(P_{\text {ont }}=4.86 \mu \mathrm{s}, P_{\text {offt }}\right.$ $=6.97 \mu \mathrm{s}, I_{P}=15 \mathrm{~A}$ and $\left.U_{P}=25 \mathrm{~V}\right)$, required target roughness values $R a_{T, F R 2}=2.5 \mu \mathrm{m}$ were achieved. 
The total composite desirability when using RSM for predicted responses or the roughness target was at level 1. This means that the response $\left(R a_{T, F R 2}\right)$ has reached an ideal state. The minimum peak count $P c_{T, F R 2}=118 \mathrm{~cm}^{-1}$ was established by calculation according to the regression Model (14) and (17), at which a coefficient of determination $R-S q$ (adj) of $99.97 \%$ and a coefficient of correlation $R=1$ were recorded.

Figure $7 \mathrm{c}$ shows that with the combination of the optimized EDT parameters $\left(P_{\text {ont }}=19.5 \mu \mathrm{s}, P_{\text {oft }}\right.$ $=38 \mu \mathrm{s}, I_{P}=19 \mathrm{~A}$ and $\left.U_{P}=25 \mathrm{~V}\right)$, required target roughness values $R a_{T, F R 3}=3.5 \mu \mathrm{m}$ were achieved. The total composite desirability when using RSM for predicted responses or the roughness target was at level 1 . This means that the $R a_{T, F R 3}$ response had reached an ideal state. The minimum peak count $P c_{T, F R 3}=78 \mathrm{~cm}^{-1}$ was established by calculation according to the regression Model (14) and (17), at which a coefficient of determination $R-S q$ (adj) of $99.97 \%$ and a coefficient of correlation $R=1$ were recorded.

Response surface optimization results confirmed that the parameters applied to the roller texturing process should be capable of repeatedly creating a texture with $R a_{T, F R 1}=1.538 \mu \mathrm{m}, R a_{T, F R 2}=2.5 \mu \mathrm{m}$ and $R a_{T, F R 3}=3.5 \mu \mathrm{m}$ with $P c_{T, F R, \min }>60 \mathrm{~cm}^{-1}$. When setting the EDT process parameters listed in Table 2, it can be assumed that the texture with $R a_{T, F R i}$ will be repeatedly achieved, ranging between 1.538 and $3.5 \mu \mathrm{m}$ and, at the same time, the peak count $P C_{T, F R i, \min }>40 \mathrm{~cm}^{-1}$, as required by Skoda. At the target roughness values ranging from 1.538 to $3.5 \mu \mathrm{m}$, the minimum number of peaks was greater than 40 -Table 3.

Optimized parameters of EDT factors were verified to reach the target value of the finishing rollers surface roughness $R a=2.5 \mu \mathrm{m}$. After applying these parameters (Table 13) the roughness values of the finishing rollers were $2.4 \pm 0.06 \mu \mathrm{m}$.

\section{Conclusions}

The main aim of this paper was to obtain optimized electro-discharge texturing parameters of rolling mill finishing rollers for surface texture finish values ranging from $R a_{T, F R}=1.539$ to $R a_{T, F R}$ $=3.5 \mu \mathrm{m}$, while at the same time, the minimum peak count should be greater than 60 according to Volkswagen and larger than $40 \mathrm{~cm}^{-1}$ according to the requirements of Skoda carmakers. The research involved a sample of 48 pieces of finishing rollers (i.e., 16 for each level of parameters), the surface of which was subjected to texturing by the EDT 2100/4500 device in a BP250 oil dielectric with eight copper electrodes at varying levels of input parameters of electro-discharge texturing (EDT), creating textures with the target roughness values $R a_{T, F R 1}=1.538 \mu \mathrm{m}, R a_{T, F R 2}=2.5 \mu \mathrm{m}$ and $R a_{T, F R 3}=3.8 \mu \mathrm{m}$ and the peak count $P c_{F R 1}=158 \mathrm{~cm}^{-1}, P c_{F R 2}=99 \mathrm{~cm}^{-1}$ and $P C_{F R 3}=68 \mathrm{~cm}^{-1}$. With the use of control charts and process capability indices $C_{p k}$, rollers were selected on which the $t$-test and the $F$-test analyses were subsequently performed. The results of the $t$-test and the F-test show that regression models obtained describe the relationships between the EDT input parameters and the $R a_{F R}$ and $P c_{F R}$ finishing rollers texture characteristics with a very high probability. Significance tests show that at the significance level $\alpha=0.05$, a significant effect of the EDT input parameters was noted: the duration of the technological pause $P_{\text {ont }}$, voltage $U_{p}$, current $I_{p}$ and the length of the technological pause on the texture characteristics $R a_{F R}$ and $P c_{F R}$. Influence of mutual interactions of individual input factors on the roughness $R a_{F R}$ and the peak count $P C_{F R}$ at significance level $\alpha=0.05$ was not recorded. The Pareto chart shows that the greatest influence on the roller roughness $R a_{F R}$ was that of duration of the technological pause and the lowest was that of the current $I_{p}$. In terms of the peak count and $P c_{F R}$, the effect of individual factors was at the same level. The resulting roughness of the finishing rollers or the amount of material removed depended on the energy of the electric discharge. With very small changes in $P_{\text {ont }}$ from 4.29 to $4.86 \mu \mathrm{s}$, in $P_{\text {offt }}$ from 6.32 to $6.97 \mu$ s but larger current changes $I_{p}$ from 4.47 to $15.1 \mathrm{~A}$ and voltage $U_{p}$ from 8.1 to $25 \mathrm{~V}$ there was a change in $\Delta R a_{F R}$ by $0.961 \mu \mathrm{m}$ (from 1.539 to $2.5 \mu \mathrm{m}$ ) and $\Delta P C_{F R}$ by $38 \mathrm{~cm}^{-1}$ (from 156 to $118 \mathrm{~cm}^{-1}$ ). At the same voltage $U_{p}=25 \mathrm{~V}$ and current change $I_{p}$ from 15.1 to $19 \mathrm{~A}$ but with major changes in $P_{\text {ont }}$ from 4.86 to $19.53 \mu \mathrm{s}, P_{\text {offt }}$ from 6.97 to $38 \mu \mathrm{s}$, a change in roughness $\Delta R a_{F R}$ was also achieved by about $1 \mu \mathrm{m}$ (from $R a_{F R} 2.5$ to $3.5 \mu \mathrm{m}$ ) and a change in $P c_{F R}$ by 40 peaks per $\mathrm{cm}$ (from 
118 to $\left.78 \mathrm{~cm}^{-1}\right)$. Thus, based on the results obtained, it could be concluded that a greater effect was achieved by setting the input parameters of EDT at their lower level than at their upper level.

Optimal values of input parameters $I_{P}, U_{P}, P_{\text {ont }}$ and $P_{\text {offt }}$ were established by the RSM method. Based on the verification of RSM results, it can be stated that the optimal (ideal) values of the target roughness characteristics have been achieved: $R a_{T, F R}=1.539 \mu \mathrm{m}$ and, at the same time, the minimum values $P c_{T, F R, \min }=156 \mathrm{~cm}^{-1}$ when setting the current $I_{P}=4.47 \mathrm{~A}, U_{P}=8.1 \mathrm{~V}, P_{\text {ont }}=4.29 \mu \mathrm{s}, P_{\text {offt }}=$ $6.32 \mu \mathrm{s} ; R a_{T, F R}=2.5 \mu \mathrm{m}$ and, at the same time, the minimum values $P{ }_{C_{T, F R, m i n}}=118 \mathrm{~cm}^{-1}$ when setting the current $I_{P}=15.1 \mathrm{~A}, U_{P}=25, P_{\text {ont }}=4.86 \mu \mathrm{s}$ and $P_{\text {offt }}=6.97 \mu \mathrm{s} ; R a_{T, F R}=3.5 \mu \mathrm{m}$ and, at the same time, the minimum values $P_{c_{T, F R, \min }}=78 \mathrm{~cm}^{-1}$ when setting the current $I_{P}=19 \mathrm{~A}, U_{P}=25 \mathrm{~V}, P_{\text {ont }}=19.53 \mu \mathrm{s}$ and $P_{\text {offt }}=38 \mu \mathrm{s}$.

The results obtained further show that with increasing roughness $R a_{F R}$ a decrease in the $P c_{F R}$ peak count was observed as was a good correlation between these roller texture characteristics. The obtained set of input parameters can be used to optimize other output characteristics of the EDT process such as cost and can also form the basis for designing adaptive process control strategies for EDT process of finishing rollers.

Author Contributions: Conceptualization and methodology, E.E.; software, J.K.; formal analysis and validation, E.E. and J.K.; writing—original draft preparation, E.E. and M.T.; writing-review and editing, E.E. and M.T. All authors have read and agreed to the published version of the manuscript.

Funding: This research received no external funding.

Acknowledgments: The work was accomplished under the grant project VEGA 2-0080-19 "Prediction of weldability and formability for laser welded tailored blanks made of combined high strength steels with CAE support" and project APVV-0273-12 "Supporting innovations of autobody components from the steel sheet blanks oriented to the safety, the ecology and the car weight reduction".

Conflicts of Interest: The authors declare no conflict of interest.

\section{References}

1. Batalha, D.F.; Stipkovic Filho, M. Quantitative characterization of the surface topography of cold rolled sheets-new approaches and possibilities. J. Mater. Process. Technol. 2001, 113, 732-738. [CrossRef]

2. Hong, M.H.; Tark, H.J.; Park, J.S.; Paik, D.J. Improvement of surface texture on the hot dip galvanized and galvannealed steel sheets. La Metallurgia Italiana 2012, 6, 9-13.

3. Grochea, P.; Calliesb, T. Tribology in Sheet Metal Forming with Regard to Challenges in Lightweight Construction. Adv. Mater. Res. 2005, 6-8, 93-100. [CrossRef]

4. Evin, E.; Kmec, J.; Fechová, E. Optimizing of electric discharge texturing parameters of rolls of the rolling mill of steel sheets. Appl. Mech. Mater. 2003, 420, 78-84. [CrossRef]

5. Müll, K.; Routschek, T. Topocrom Texturing: Technology and Advantages. Available online: http://www. topocrom.com/content/pdf/Baosteel_BAC_Topocrom.pdf (accessed on 27 November 2019).

6. Terpák, L.; Dorčák, J.; Revaj, J. Quality Control of the Electro-Discharge Texturing. Metalurgija 2010, 49, 19-22.

7. Gorbunov, A.V.; Belov, V.; Begletsov, D.O. Texturing of rollers for the production of auto-industry sheet. Steel Transl. 2009, 39, 696-699. [CrossRef]

8. Faisal, N.; Kumar, K. Optimization of Machine Process Parameters in EDM for EN 31 Using Evolutionary Optimization Techniques. Technologies 2018, 6, 54. [CrossRef]

9. Abu Qudeiri, J.E.; Saleh, A.; Ziout, A.; Mourad, A.-H.I.; Abidi, M.H.; Elkaseer, A. Advanced Electric Discharge Machining of Stainless Steels: Assessment of the State of the Art, Gaps and Future Prospect. Materials 2019, 12, 907. [CrossRef]

10. Straka, L.; Corný, I.; Pitel', J.; Hašová, S. Statistical Approach to Optimize the Process Parameters of HAZ of Tool Steel EN X32CrMoV12-28 after Die-Sinking EDM with SF-Cu Electrode. Metals 2017, 7, 35. [CrossRef]

11. Salcedo, A.T.; Arbizu, I.P.; Pérez, C.J.L. Analytical Modelling of Energy Density and Optimization of the EDM Machining Parameters of Inconel 600. Metals 2017, 7, 166. [CrossRef]

12. Liang, J.F.; Liao, Y.S.; Kao, J.Y.; Huang, C.H.; Hsu, C.Y. Study of the EDM performance to produce a stable process and surface modification. Int. J. Adv. Manuf. Technol. 2018, 95, 1743-1750. [CrossRef] 
13. Gaikwad, M.U.; Krishnamoorthy, A.; Jatti, V.S. Investigation and Optimization of Process Parameters in Electrical Discharge Machining (EDM) Process for NiTi 60. Mater. Res. Express 2019, 6, 65707. [CrossRef]

14. Kumar, S.; Kundu, S.; Chaudhary, R. Optimization of Process Parameter and Experimental Investigation of MRR on H-13 Die Tool Steel using EDM with Application of Taguchi Technique. Int. J. Eng. Manage. Res. 2014, 4, 162-167.

15. Świercz, R.; Oniszczuk-Świercz, D. Experimental Investigation of Surface Layer Properties of High Thermal Conductivity Tool Steel after Electrical Discharge Machining. Metals 2017, 7, 550. [CrossRef]

16. Sabyrov, N.; Jahan, M.P.; Bilal, A.; Perveen, A. Ultrasonic Vibration Assisted Electro-Discharge Machining (EDM)-An Overview. Materials 2019, 12, 522. [CrossRef]

17. Montgomery, D.C. Design and Analysis of Experiments, 8th ed.; Wiley Publication: New York, NY, USA, 2012; p. 752.

18. Roy, R.K. Design of Experiments Using the Taguchi Approach: 16 Steps to Product and Process Improvement, 1st ed.; John Wiley \& Sons: New York, NY, USA, 2001.

19. Ryan, T.P. Modern Experimental Design, 1st ed.; John Wiley \& Sons: New York, NY, USA, 2007.

20. Warrender, T.E.; Aspinwall, D.K.; Dewes, R.C.; Simao, J.M.T.; Aspinwall, E.M.; Scamans, G. Difficulties in characterising roll surfaces. Trans. Eng. Sci. 2003, 44, 56-64. [CrossRef]

21. Ishfaq, K.; Ahmad, N.; Jawad, M.; Ali, M.A.; Al-Ahmari, A.M. Evaluating Material's Interaction in Wire Electrical Discharge Machining of Stainless Steel (304) for Simultaneous Optimization of Conflicting Responses. Materials 2019, 12, 1940. [CrossRef] [PubMed]

22. Sun, Y.; Gong, Y.; Liu, Y.; Li, Q.; Zhou, Y. Experimental study on surface characteristics and improvement of microelectrode machined by low speed wire electrical discharge turning. Arch. Civ. Mech. Eng. 2017, 17, 964-977. [CrossRef]

23. Godočíková, E.; Leško, M.; Baláž, P. Usage of a statistical method of designing factorial experiments in the mechanical activation of a complex CuPbZn sulphide concentrate. Acta Montanistica Slovaca 2003, 8, 134-138.

24. ISO. ISO 12085:1996(en) Geometrical Product Specifications (GPS)—Surface Texture: Profile Method—Motif Parameters; ISO: Geneva, Switzerland, 1996.

25. Khan, R.M. Problem Solving and Data Analysis Using Minitab: A Clear and Easy Guide to Six Sigma Methodology, 1st ed.; Wiley: West Sussex, UK, 2013; 484p.

26. Allen, T. Introduction to Engineering Statistics and Six Sigma: Statistical Quality Control and Design of Experiments and Systems, 1st ed.; Springer: London, UK, 2006; p. 529.

27. Ishfaq, K.; Mufti, N.A.; Mughal, M.P.; Saleem, M.Q.; Ahmed, N. Investigation of wire electric discharge machining of stainless-clad steel for optimization of cutting speed. Int. J. Adv. Manuf. Technol. 2018, 96, 1429-1443. [CrossRef]

28. Ikram, A.; Mufti, N.A.; Saleem, M.Q.; Khan, A.R. Parametric optimization for surface roughness, kerf and MRR in wire electrical discharge machining (WEDM) using Taguchi design of experiment. J. Mech. Sci. Technol. 2013, 27, 2133-2141. [CrossRef]

29. Shah, C.D.; Mevada, J.R.; Khatri, B.C. Optimization of Process Parameter of Wire Electrical Discharge Machine by Response Surface Methodology on Inconel-600. Int. J. Emerging Technol. Adv. Eng. 2013, 3, 260-267.

(C) 2020 by the authors. Licensee MDPI, Basel, Switzerland. This article is an open access article distributed under the terms and conditions of the Creative Commons Attribution (CC BY) license (http://creativecommons.org/licenses/by/4.0/). 